\title{
La crónica y las tradiciones peruanas: la reelaboración de acontecimientos y peripecias
}

\author{
Eduardo Huárag Álvarez \\ Pontificia Universidad Católica del Perú \\ ehuarag@pucp.pe \\ Lima-Perú
}

\section{Resumen}

El presente ensayo explora de qué modo se producen las interrelaciones entre las crónicas del Inca Garcilaso de la Vega y del Palentino, fundamentalmente, y las Tradiciones peruanas de Ricardo Palma. Se trata de indagar cuál es el grado de dependencia de Palma con las crónicas de los autores mencionados y en qué aspectos se produce tal relación. Así pues, al hacer el análisis de varias tradiciones, encontraremos los vínculos de las mismas con el planteamiento argumental de la crónica, pero a su vez se podrá percibir que hay un proceso de mutación o adecuación que hace particular el estilo de Palma. Ciertamente, los episodios anecdóticos en las crónicas no son el propósito central; mientras que en Palma, cada episodio se constituye en un relato autónomo, con la estructura y tratamiento que exige un relato breve.

Palabras clave: crónicas, relato, anecdótico, episodio, discurso.

\section{Abstract:}

This essay explores how the interrelations between the chronicles of the Inca Garcilaso de la Vega and the Palentino and the Peruvian Traditions of Ricardo Palma take place. It would be a question of investigating the degree of dependence of Palma with the chronicles of the mentioned authors and in what aspects there is such a relationship. Thus, when making the analysis of several traditions, we will find the links of the traditions with the approach of the chronicle, but in turn, it can be perceived that there is a process of mutation or adaptation that makes Palma's style particular. Certainly, anecdotal episodes in the chronicles are not the central purpose in the chronicler; while for Palma, each episode constitutes an autonomous story, with structure and treatment that requires a short story.

Keywords: chronica, story, anecdotal, episode, specch 
Eduardo Huárag Álvarez (Perú): Doctor en Lengua y Literatura por la Pontificia Universidad Católica del Perú. Maestría en Comunicaciones por la Universidad de Andalucía (España). Profesor Asociado del departamento de Humanidades de la Universidad Católica del Perú. Ha sido profesor visitante en la Universidad de Burdeos, la Universidad de Múnich y la Universidad de São Paulo. Ha publicado La cultura oral en la narrativa hispanoamericana, Mitos de origen y el trasmundo en las culturas prehispánicas y amazónicas, entre otros. 
Palma es un narrador que a través de la sucesiva publicación de sus Tradiciones peruanas buscará una relación de complementación entre el relato histórico y el relato literario. Por eso recurre, no pocas veces, al denominado "parrafillo histórico". Pero los vínculos de Palma con la historia no se producen solo por los datos que ofrece el "parrafillo histórico". Los vínculos hay que buscarlos también en los textos de donde extrae el argumento de sus relatos. Este es un aspecto que pocas veces se menciona. La crítica ha reiterado el estilo ameno, el humor, el ingenio y la perspectiva del narrador criollo. Nosotros queremos establecer la interrelación que existe entre las crónicas y el relato literario. Para el estudio comparativo hemos escogido algunas de las tradiciones de Palma y -según sea el caso- las crónicas del Inca Garcilaso o del Palentino.

Hay que señalar que el proceso de traslación de un argumento o peripecia histórica a un relato literario no es tan sencillo. No se trata de una simple transposición. El narrador puede mantener gran parte de los sucesos del hecho anecdótico, pero el texto literario exige una estructura, una secuenciación organizada bajo el principio de intensidad narrativa. Palma, que se ha propuesto escribir un relato breve (como lo hicieron muchos románticos que se inspiraban en historias del pasado) realiza la adecuación aproximadamente 350 años después de sucedidos los hechos.

Por otro lado, téngase en cuenta que cuando Palma escribe sus tradiciones ya se han configurado los rasgos que caracterizan al relato breve. Es cierto que Palma adecúa el relato breve en ese estilo propio que denomina Tradiciones peruanas. La traslación, por tanto, supondría un proceso en el que se parte de un episodio anecdótico y probablemente un personaje; pero luego el narrador debe construir el relato literario combinando 
la recreación ficcional con los referentes históricos, tal como los concebía Palma. Así pues, más allá del argumento, debemos apreciar en la traslación esos elementos que hacen sugestivas y entretenidas las tradiciones.

\section{El relato en versión de Palma: “iAy, cuitada! y iguay de lo que aquí andaba!"}

En sus Tradiciones, Palma le da importancia especial a los refranes y decires. Cree que representan la cultura popular y que la literatura debe expresar lo que vive y existe en el imaginario del pueblo. Se trata de acercar la narrativa a la idiosincrasia popular. Por eso no es extraño que algunas tradiciones, como en este caso, lleven el refrán como título.

El relato empieza comentando que Carbajal decidió visitar a un vecino del Cusco.

-iHola, seor tejedor! -le dijo don Francisco-. Tejida tiene ya Cantillana la cuerda con que ha de ahorcarle. Que venga el padre Márquez y lo confiese (1968, p. 97).

La decisión de Carbajal preocupó al vecino. Pensó, muy rápido, cómo hacerle cambiar la decisión. Por entonces, se sabía que Carbajal tenía codicia por los metales preciosos, por lo que se permitió hacerle una propuesta:

-Antes que con el capellán quisiera confesar con vueseñoría.

Y acercándose al oído de Carbajal, le dijo en voz muy baja:

-Doy dos mil pesos de oro por rescate de mi vida. ¿Acomoda el trato? (ibíd.).

Carbajal se sintió más que feliz con la propuesta, pero como había que ser discretos, les dijo a sus capitanes: 
-iLoado sea el Señor, que ha inspirado a vuesa merced a tiempo para revelarme su secreto! Y, pues disfrutaba de privilegio de corona, vaya vuesa merced mucho con Dios, y esté seguro que, si somos contra el rey, no somos contra la Iglesia (ibíd.).

Ahora bien, como a Palma no le interesa solo caracterizar un personaje sino también construir el lado legendario de Carbajal, hará una reseña de lo que le aconteció al personaje mencionado cuando aún estaba en Europa:

Cuentan de Carbajal que, en el saco de Roma, mientras sus compañeros andaban a caza de alhajas y disputándose entre ellos las prendas del botín, don Francisco se ocupaba tranquilamente en trasladar a su posada los protocolos de un escribano. Este, interesado en rescatar su archivo, pagó a Carbajal mil quinientos ducados. La soldadesca, que lo había calificado de loco, porque se apoderó de pergaminos y papeles viejos, tuvo que confesar que procedió con talento, pues nadie logró en el saco de Roma provecho mayor que el obtenido por nuestro Demonio de los Andes. Las monedas del cartulario sirviéronle para trasladarse a América (ibíd.).

Como no todo sale como se espera, a pesar de ser vencedor en Pocona, se dice que los derrotados pasaron sobre el equipaje de don Francisco y al huir se llevaron los tejos de oro del mencionado. Y ocurrió que la casualidad o el destino lo puso ante Pero Hernández, uno de los que se había llevado sus tejones de oro. Y ese personaje apostaba en el juego de dados uno de los famosos tejones. Fue don Francisco al lugar y dijo:

-Jueguen y huelguen los caballeros y estése queda esa moneda, que juro cierto que es muy buena.

Y puso la mano sobre el tejuelo, que pesaba quinientos castellanos, añadiendo alegremente: 
-iAy cuitada! iY guay de lo que aquí andaba! iA las crines, corredor! iAhora, por mi vida, que te va el recuero! (p. 98).

Y como la moneda, el tejo de oro, era de Pero Hernández, le dijo:

-Venga acá, señor Pero Hernández, que quiérole contar un cuento (ibíd.).

Entonces el narrador procede a insertar un episodio anecdótico que venía muy al caso y del que se derivó la frase que titula el relato.

-Habrá de saber, señor Pero Hernández, que una honrada dueña quería mucho a su marido, y murió éste, y un día, barriendo la casa, topó con unas calzas viejas del difunto, y cortando la bragueta púsola en un agujero, y cada vez que barría la casa, cuando llegaba al agujero comenzaba a bailar, cantando: "Ay, cuitada! iY guay de lo que aquí andaba!" (ibíd.).

Llama la atención el dominio que tiene el narrador para insertar una pequeña historia dentro de otra historia; es lo que en Narratología se entiende como "técnica de las cajas chinas".

El caso es que la moneda era de Pero Hernández y don Francisco no tarda en enrostrarle la ilícita manera cómo obtuvieron la moneda:

-Dígame ahora, señor Pero Hernández, ¿qué es de una carga de oro que estaba con este tejuelo, pues me faltan otros veinte de la familia?

-Señor, yo no lo sé -contestó el soldado-, que este tejuelo me tocó en el reparto. En cuanto a los otros, que cada sacristán doble por su difunto, que yo no tengo por qué. 
Pues búsqueme a los hermanos y encuéntrelos, por su vida, ladroncillo de barjuleta" (ibíd.).

Palma hace en sus relatos una simbiosis de pequeña historia, relato popular y frases o refranes que han quedado -mucho tiempo después- en el imaginario. Por eso se dice que Carbajal salió del garito poniendo la nota amena: "iAy cuitada! iY guay de lo que aquí andaba!" (ibíd.).

El tradicionista, como narrador, no dejaba la historia inconclusa. Hacía falta que dijera lo que hizo Pero Hernández. El soldado: "aquella misma noche tomó el camino del humo, temeroso de que a don Francisco se le antojase más tarde cobrar en su pescuezo el precio de los tejuelos" (ibíd.).

\subsection{La versión en la crónica del Palentino}

En el capítulo X de su crónica Primera y segunda parte de la historia del Perú, Diego Fernández el Palentino refiere que los sucesos ocurrieron en Cotabamba. El cronista agrega dos atributos de Carbajal: la valentía y el autoritarismo. Pero vayamos al episodio en el que se pronunció la frase que dio título al relato. Se sabe que Carbajal ponía mucho empeño en recuperar las pertenencias perdidas:

Ponía Francisco de Carvajal gran diligencia por saber de su ropa y oro que le habían tomado, y traía espías aquí en Cotabamba para ello; y fue avisado secretamente cómo en un toldo estaba un soldado de la entrada jugando un tejuelo de oro. Carvajal fue luego para allá y entróse de presto y vio que estaban jugando á la dobladilla, y díjoles: "Jueguen y huélguense los caballeros y estése queda la moneda que es muy buena", y tomó un tejuelo de oro de ochocientos castellanos que jugaba Pero Hernández, y díjole: “iAh!, señor Pero Hernández, quiérole contar un cuento. Habrá 
de saber que una buena dueña quería mucho á su marido y muriósele, y un día, barriendo la casa, topó con unas calzas viejas suyas y quitando dellas la bragueta pasóla dentro de un agujero, y cada día barría su casa, y cuando llegaba al agujero comenzaba a cantar y decir: iAy, cuitada, y guay de lo que aquí andaba!"; y así Carvajal tomó su tejuelo en las manos y replicábale cantando: "iY guay de lo que aquí andaba!" (1914, p. 61).

Y Fernández, más conocido como el Palentino, gran narrador, hace la asociación de la frase con la circunstancia en la que Carbajal ha entrado al garito y ha tomado el tejón de oro:

Luego se volvió al soldado y díjole: "Así que, señor Pero Hernández, ¿qué es de una carga de oro que estaba con este tejuelo, que me faltan más de otros veinte como éste? Respondió Pero Hernández: "Señor, yo no lo sé y ese tejuelo yo lo gané. Dijo Carvajal: "Pues, señor, búsqueme luego los otros y quédese con Dios”; y llevóse el tejuelo en la mano. Pero Hernández lo tuvo por bien porque se temió que Carvajal le mandara ahorcar (ibíd.).

Como se habrá podido apreciar, el planteamiento argumental es semejante, especialmente en la referencia de las calzas viejas y el hecho de ponerlas en el agujero y que cada vez que pasaba por el lugar pronunciaba el refrán aludido. También coincide en que, el dueño del tejuelo de oro, en cuanto Carbajal le envió a buscar a los que tenían los otros tejuelos, desapareció para no ser ahorcado.

Nótese que el Palentino, luego de referir esta historia sobre Carbajal, mencionará otras, pero sin la noción de relato corto que recién se conoció en el siglo XIX. A su manera, el Palentino menciona que uno de los soldados que Carbajal tenía en su regimiento apellidaba Matamoros y que era precisamente el que 
le había herido en batalla. Carbajal, enterado del hecho, mandó a un grupo de soldados a estorbar a los que iban a Chile. En esa delegación enviaba a Matamoros. El soldado se excusó para no ir. A Carbajal no le gustó que el soldado no cumpliera su orden:

y como Carvajal buscaba ocasión de matarle, preguntó al sargento: si Matamoros había ido, y diciendo el sargento que aún no eran partidos los soldados, y que Matamoros no iba por no perder la plata, mandóle luego llamar, y díjole: "Señor Matamoros, yo quisiera que fuérades con vuestros compañeros, y veo que vos no queréis ir; pues ni sea lo que yo quiero, que es ir, ni lo que vos queréis, que es quedar, sino que como entre amigos se tome un medio, que ni vayáis, ni quedéis, y este medio será que os ahorquen"; y luego lo mandó efectuar, diciendo que lo hacía porque todos entendiesen que en lo que él mandaba no había de haber réplica; y jamás mostró haber entendido que Matamoros le había herido (1914, p. 62).

Con lo cual se reconfirma que Carbajal era vengativo y cruel. Pocas veces perdonaba a sus enemigos. Por otro lado, como procedimiento narrativo, esto se conoce como "técnica de la caja china", en tanto que se agrega una historia en otra esbozada anteriormente.

\section{Las tradiciones de Palma en cinco relatos acerca de "El demonio de los Andes"}

En sus Tradiciones, Palma está interesado en hacer una reseña biográfica de Francisco de Carbajal y convertirlo en personaje legendario. Para ello no puede dejar de hacer mención al lugar de nacimiento, aventuras, batallas y otros pormenores de la enigmática vida de Carbajal. El relato se inicia dando referencias de la procedencia del personaje: 
Arévalo, pequeña ciudad de Castilla la Vieja, dio cuna al soldado que, por su indómita bravura, por sus dotes militares, por sus hazañas que rayan en lo fantástico, por su rara fortuna en los combates y por su carácter sarcástico y cruel, fue conocido, en los primeros tiempos del coloniaje, con el nombre de Demonio de los Andes (1968, p. 76).

Luego de dar referencias biográficas de Carbajal, la narración concluye, claro está, con la derrota del maese en la batalla de Sacsahuamán y su ejecución por orden de La Gasca.

Lo importante es advertir que Palma debió intuir que había material suficiente como para derivar varias tradiciones. Por eso anuncia: "vamos a presentarles, en una docena de tradiciones históricas, cuanto de original y curioso conocemos sobre el carácter y acciones del popular Demonio de los Andes" (1968, p. 82).

Pese a la advertencia que lo que quiere hacer es reconstruir la biografía de un militar de éxito y braveza, el narrador no deja de recrear algún episodio significativo.

Vamos a consignar cinco relatos que corresponden a las Tradiciones peruanas y seguidamente, el relato que figura en la crónica.

\section{Primera secuencia según el relato de las Tradiciones:}

Cuéntase que, en el Cuzco, doña María Calderón, esposa de un capitán de las tropas de Centeno, se permitía con mujeril indiscreción tratar a Gonzalo de tirano, y repetía en público que el rey no tardaría en triunfar de los rebeldes.

-Comadrita -le dijo Carbajal en tres distintas ocasiones-, tráguese usted las palabras; porque si no contiene su maldita sin-hueso la hago matar, como hay Dios, sin que la valga el parentesco espiritual que conmigo tiene. 
Luego que vio la inutilidad de la tercera monición, se presentó el maestre en casa de la señora:

-Sepa usted, señora comadre, que vengo a darla garrote.

Y después de haber expuesto el cadáver en una ventana, exclamó:

-iCuerpo de tal, comadre cotorrita, que si usted no escarmienta de ésta, yo no sé lo que me haga! (1968, p. 79).

\section{Primera secuencia según el relato de la crónica:}

La crónica en la que el narrador hace referencia a doña María Calderón, la encontramos en el Inca Garcilaso. Primero señala que la señora sufrió la pena del garrote y que fue colgada de la ventana. Pero el Inca se explaya y anota:

No dijimos entonces las palabras y razones que de una parte a otra se dijeron, por ir con la corriente de la historia y no ser aquél lugar de gracias. Ahora se pondrán las que allí faltaron. Doña María Calderón, aunque estaba en poder de sus enemigos, hablaba muy al descubierto contra Gonzalo Pizarro y sus tiranías, y no era otra su plática ordinaria sino decir mal dél. Carvajal, que lo supo, le envió amonestar una y dos y más veces que se dejase de aquellas gracias, que ni eran discretas ni provechosas para su salud. Lo mismo le dijeron otras personas, que temían su mal y daño. Doña María Calderón, en lugar de refrenarse y corregirse, habló de allí en adelante con más libertad y desacato, de manera que obligó a Carvajal a ir a su posada para remediarlo, y le dijo: “¿Sabe vuesa merced, señora comadre (que cierto lo era), cómo vengo a darle el garrote? Ella, usando de sus donaires y pensando que Carvajal se burlaba con ella, respondió: "Vete con el Diablo, loco borracho, que aunque sea burlando no lo quiero oír". Carvajal dijo: "No burlo, 
cierto, que para que vuesa merced no hable tanto y tan mal, vengo a que le aprieten la garganta; y para que vuesa merced lo crea, mando y requiero a estos soldados etíopes que le den garrote", que eran tres o cuatro negros que siempre traía consigo para semejantes hazañas. Los cuales la ahogaron luego y la colgaron de una ventana que salía a la calle. Carvajal, pasando por debajo della, alzó los ojos y dijo: "por vida de tal, señora comadre, que si vuesa merced no escarmienta de ésta, que no sé qué me haga” (2007, p. 844).

Nótese que la actitud impertinente de María Calderón es la misma. Ambos (el Inca Garcilaso y Palma) recrean la historia (con el relato de lo acontecido y diálogos entre los personajes), aunque el estilo de cada uno es diferente.

\section{Segunda secuencia según el relato de las Tradiciones:}

Los hechos suceden el 9 de abril de 1548, cuando los rivales estaban dispuestos a batallar en Sacsahuana. Lo lamentable es que casi no hubo batalla porque se produjo un hecho inusitado: la deserción de los soldados del regimiento de Carbajal. Dice el narrador:

Apenas rotos los fuegos, se pasaron al campo de Gasca el segundo jefe Cepeda y el capitán Garcilaso de la Vega, padre del historiador. La traición fue contagiosa, y el licenciado Gasca, sin más armas que su breviario y su consejo de capellanes, conquistó a Saxsahuamán laureles baratos y sin sangre. No fueron el valor ni la ciencia militar, sino la ingratitud y la felonía los que vencieron al generoso hermano del marqués Pizarro.

Cuando vio Carbajal la traidora deserción de sus compañeros, puso una pierna sobre el arzón y empezó a cantar el villancico que tan popular se ha hecho después: 
Los mis cabellicos, maire, uno a uno se los llevó el aire.

iAy pobrecicos

los mis cabellicos! (1968, p. 79).

Destáquese, una vez más, el interés de Palma por registrar los dichos y decires que se hicieron populares. Coplas memorables que quedan en el imaginario popular como aquel: "Pues señor gobernador/ mírelo bien por entero/, que allá va el recogedor/, y aquí queda el carnicero".

\section{Segunda secuencia según el relato de la crónica:}

Se dice que, en el momento que debía iniciarse la batalla, Gonzalo Pizarro pudo observar que su tropa se pasaba al enemigo. Ante ello, Carbajal soltó esos versos que consignan los cronistas y que muestran la impotencia ante la traición:

no cesaban de pasarse al escuadrón real los soldados que podían, así infantes como caballos. Francisco de Carvajal, viendo que por no haberle creído Gonzalo Pizarro se iba perdiendo a toda prisa, empezó a cantar en voz alta:

Estos mis cabellicos, madre,

Dos a dos me los lleva el aire (Garcilaso, 2007, p. 814)

Otro detalle es que Garcilaso, como cronista, ofrece información pormenorizada de la deserción:

De la manga de arcabuceros que estaban a la mano derecha del escuadrón de Gonzalo Pizarro, salieron treinta y tantos arcabuceros, mostrándose muy fieles, dando a entender que iban a trabar escaramuza con los contrarios. Mas viéndose algo apartados de los suyos, corrieron a toda furia a meterse en el escuadrón real. Y estos y los que antes se habían huido, 
todos decían al General y a sus ministros que no saliesen a pelear, sino que se estuviesen quedos, que muy presto se pasarían todos los de Pizarro y lo dejarían solo. Y así salió el hecho, porque Gonzalo Pizarro mandó a treinta de a caballo que fuesen en pos de los peones y los detuviesen; mas ellos lo hicieron tan esforzadamente, que se fueron a entregar a los del Presidente así como los infantes [...]

Carvajal no cesaba de su canto, que a cada cuadrilla que se les iba lo entonaba de nuevo. Los piqueros que estaban en el escuadrón viendo los arcabuceros que del un lado y del otro de su escuadrón se habían huido, y que ellos no podían fingir que iban a escaramuzar con los contrarios, soltaron las picas todos a una y echaron a huir por diversas partes, con que se acabó de deshacer el escuadrón de Gonzalo Pizarro (pp. 814-815).

Aquí Garcilaso es más minucioso en los sucesos de la deserción. Incluso, hay que destacar que estamos ante un estilo que permite "visualizar" lo que se relata. Otro hecho importante es la referencia a la copla que repetía Carbajal. Al parecer existían diferentes versiones de la copla que pronunció Carbajal. En todo caso, en boca y memoria de la cultura oral, llegó modificada a los oídos de Palma.

\section{Tercera secuencia según el relato de las Tradiciones:}

En pleno campo de batalla, cayó al suelo Carbajal y le rodearon los enemigos para dar cuenta de él. Centeno estaba cerca e intervino para que no le mataran en ese momento. Entonces se produce un diálogo que consigna el narrador:

-¿Quién es vuesa merced que tanta gracia me hace?

-iNo me conoce vuesa merced? -contestó el otro con afabilidad-. Soy Diego Centeno. 
-iPor mi santo patrón! -replicó el veterano aludiendo a la retirada de Charcas y a la batalla de Huarina-. Como vi siempre a vuestra merced de espaldas no le conocía viéndole la cara (1968, p. 79)

Feroz ironía de Carbajal. Confirma, con la gracia que le caracteriza, la función traidora de Centeno.

\section{Tercera secuencia según el relato de las crónicas:}

Habiendo perdido la guerra, Carbajal se vio rodeado de soldados enemigos. Centeno salió a defenderle. Es importante señalar que el Inca Garcilaso refiere estos hechos que ha encontrado en el capítulo 90 del Palentino:

Asimesmo llegaba mucha gente, y le decían injurias y oprobios, representándole cosas que había hecho. A lo cual todo Carvajal callaba, y Diego Centeno reprehendía mucho a los que le ofendían, por lo cual Carvajal le miró y dijo: "Señor, ¿quién es vuesa merced que tanta merced me hace?". A lo cual Centeno respondió: “¿Qué no conoce vuesa merced a Diego Centeno?”. Dijo entonces Carvajal: "Por Dios, señor, que como siempre vi a vuesa merced de espaldas, que agora, teniéndole de cara, no le conocía" (dando a entender que siempre había de él huido) (Garcilaso, 2007, p. 830).

Pese a la ironía de Carbajal, Centeno parece no entender de sutilezas y persiste en ser generoso con el maese: "que si había en que hacer alguna cosa por él, que se lo dijese, porque lo haría con voluntad" (ibíd.). Y claro, Carbajal que tiene honor y dignidad, le comenta que no es un ciudadano que le teme a la muerte, ni es de los ciudadanos que se ponen a suplicar: "Señor Diego Centeno, no soy tan niño o muchacho para que con temor de la muerte cometa tan gran poquedad y liviandad como sería rogar a vuesa merced hiciese algo por mí" (p. 831). 


\section{Cuarta secuencia según el relato de las Tradiciones:}

Una vez apresado fueron muchos los que se acercaron a exigirle el pago de deudas o perjuicios ocasionados. Carbajal se mantuvo firme, pese a la traición de sus subordinados. Antes bien, encontró la manera de responder a algunos de sus acreedores.

Un mercader, que se quejaba de haber sido arruinado por don Francisco, empezó a insultarlo:

$-¿ Y$ de qué suma le soy deudor?

-Bien montará a veinte mil ducados.

Carbajal se desciñó con toda flema la vaina de la espada (pues la hoja la había entregado a Pedro de Valdivia al rendírsele prisionero), y alargándola al mercader, le dijo:

-Pues, hermanito, tome a cuenta esta vaina y no me vengan con más cobranzas; que yo no recuerdo en mi ánima tener otra deuda que cinco maravedises a una bruja bodegonera de Sevilla, y si no se los pagué fue porque cristianaba el vino, y me expuso a un ataque de cólicos y cámaras (1968, p. 80).

\section{Cuarta secuencia según el relato de la crónica:}

Mientras Carbajal está preso y a poco de ser ejecutado fueron a reclamarle por deudas o perjuicios ocasionados. En la crónica de Garcilaso, sobre este episodio se dice:

Estando Carbajal en su prisión llegó a él un mercader, y mostrando mucho sentimiento, le dijo: "Los soldados de vuesa merced me robaron en tal parte tantos mil ducados de mercadería. Vuesa merced, como capitán dellos, está obligado a restituírmelos. Yo le encargo la conciencia, que, pues ha de morir presto, me pague esta deuda". Carvajal, mirándose a sí, vio en los tiros del talabarte la vaina que 
le dejaron cuando le quitaron la espada, y, sacándola de su lugar, se la dio al mercader, diciéndole: “Tomá esto, hermano, para principio de paga, que no me han dejado otra cosa". Díjole esto para darle a entender su simplicidad de pedirle restitución de millares de ducados a quien no poseía más que una vaina de espada. Poco después que aquel se fue, entró otro con la misma demanda. Carvajal, no teniendo con qué le pagar, respondió que no se acordaba deber otra deuda sino medio real a una bodeguera de la Puerta del Arenal de Sevilla. Dijo esto por responder con un disparate a otro tal como era pedirle restitución a quien, como ellos habían visto, no le habían dejado ni capa ni sombrero con qué cubrir la cabeza, que todo se lo habían saqueado los vencedores. Que, bien mirado, lo más rico del despojo de aquel día fue lo que Carvajal perdió, porque siempre traía su hacienda consigo, y ésa en oro y no en plata, porque hiciese menos bulto (p. 824).

En esta secuencia se puede apreciar que el relato del Inca Garcilaso da referencias del episodio, pero su estilo es recargado, mientras el estilo de Palma es más ágil y coloquial. Cierto que no da muchos detalles de lo acontecido, pero para efectos del relato no parece ser indispensable.

\section{Quinta secuencia según el relato de las Tradiciones:}

Una vez leída la sentencia y a poco de la ejecutoria, Carbajal fue colocado en una cesta y a él ese hecho le causaría mucha gracia porque, ironía del destino, volvía a estar en una cesta igual como la que conoció en su infancia. Se cerraba el círculo de su vida con los mismos implementos que conoció en la niñez. Nótese su sentido de humor aun cuando está próximo a ser ejecutado. 
Cuando le colocaron en un cesto arrastrado por dos mulas para sacarlo al suplicio, soltó una carcajada y se puso a cantar

¿Qué fortuna! Niño en cuna,

viejo en cuna. iQué fortuna! (1968, p. 80)

A Carbajal no le aterraba la muerte. Guardó la compostura de los personajes que anteponen su honor. Su sorna y sarcasmo eran inevitables. Por eso el narrador señala:

Carbajal, haciendo ostentación de valor y sangre fría, dijo:

-iEa, señores, paso franco! No hay que arremolinarse y dejar hacer justicia.

Y en el momento en que el verdugo Juan Enríquez se preparaba a despachar a la víctima, ésta le dijo sonriendo:

-Hermano Juan, trátame como de sastre a sastre (1968, p. 80).

\section{Quinta secuencia según el relato de las crónicas:}

Se hace referencia a la ejecución en sí. Y fue muy comentado el sentido del humor de Carbajal, aun cuando estaba a poco de morir:

Habiéndole notificado la sentencia y todo lo que en ella se contenía, dijo sin alteración alguna: "Basta matar". Preguntó Carvajal aquel día por la mañana que de cuántos habían hecho justicia; y como le dijeron que de ninguno, dijo con mucho sosiego: "Muy piadoso es el Señor Presidente, porque si por nosotros hubiera caído la suerte, ya tuviera yo derramados por este asiento los cuartos de novecientos hombres". Acabóse con gran dificultad que se confesase, y, persuadiéndole, decía que él se entendía, y que había poco que se había confesado. Y tratando con él de restitución, se reía dello diciendo: "En eso no tengo que confesar, porque 
juro a tal que no tengo otro cargo sino medio real que debo en Sevilla a una bodegonera de la Puerta del Arenal, del tiempo que pasé a Indias". Al tiempo que le metían en una petaca en lugar de serón, dijo con mucho descuido: "Niño en cuna y viejo en cuna". Llegado ya al lugar que dél se había de hacer justicia, como iban tantos a verle y embarazaban al verdugo, les dijo: "Señores, dejen vuesas mercedes hacer justicia”. En todo mostró morir más como gentil que como cristiano. (Garcilaso, 2007, pp. 831-832).

Como podemos observar, una adecuación puede suponer una reducción del argumento o peripecia que se toma como referente (por referente entendemos la crónica del Inca Garcilaso o el Palentino). A ello se añade el estilo del tradicionista, escrito en una época en que prevalece el hecho episódico y no las frases recargadas.

\section{Un relato referido en los Anales del Cusco}

Hay un investigador importante que ha realizado la comparación entre textos referidos en las crónicas, anales o libros de historia, y la versión que finalmente presenta Ricardo Palma. Nos referimos a Merlin Compton. En La historicidad de las Tradiciones Peruanas de Ricardo Palma (2000) ha consignado varias tradiciones y las presenta de manera comparativa de modo que deriva de ello las similitudes y cambios que se observan. Sus comentarios, fundamentalmente, vinculan referencias históricas y no específicamente las diferencias entre el estilo y la estructura de una crónica y un relato literario, como el de Palma. Tampoco se detiene en establecer lo que se conoce como técnicas narrativas que Palma usa con frecuencia. Lo meritorio, en todo caso, es haber ubicado de dónde fueron extraídos los argumentos que luego figurarían como relato literario en las tradiciones. 
La diferencia con nuestro planteamiento es que a nosotros nos interesa el proceso por el cual el narrador, basándose en un esquema establecido para el relato breve (utilizado por los románticos y costumbristas), hace los ajustes al hecho anecdótico que le propone la crónica o el libro de historia. Pero la adecuación supone también aspectos de estilo para que fluya el relato según el idiolecto utilizado en el siglo XIX y no el que utilizó el Inca Garcilaso en el siglo XVI.

Reconocemos, sin embargo, que el trabajo de recolección ha sido exhaustivo. Del texto de Compton hemos extraído 2 casos que nos parecen significativos. El primero es el que se refiere a un relato acontecido en el Cusco. La fuente es el libro Anales del Cuzco, publicado por Antonio de Esquivel y Navia. Transcribimos la versión de los Anales del Cuzco:

El martes 6 de junio de 1747 se fijaron declaratorias de todas las iglesias [del Cuzco] por el señor Provisor, excomulgando a doña Antonia Peñaranda, mujer de don Pedro de Echevarría, abogado, por el lance que pasó el día domingo 4 de junio, en que habiendo entrado doña Antonia en la Catedral a oír misa, a las ocho y media de la mañana, advirtió el señor Arcediano, doctor Rivadeneyra, que la hija de esa señora (que era de nueve años de edad) llevaba cauda, y pareciéndole mal que a una niña tan tierna la vistieran con trajes profanos, reconvino a la madre alzando la voz. Respondió ella: que siendo una criatura no desdecía el traje, mayormente cuando iba creciendo y era difícil buscarle otra saya. Replicó el señor Rivadeneyra que era mal hecho, y que se fuese en hora mala, etc. Y esto alterando la voz en medio de tan numeroso concurso, por lo que la señora, avergonzada y encendida de cólera, dijo que era un zambo borrico y majadero que se entrometía en lo que no podía mandar. Contestóle el Arcediano, con gritos, que era una desvergonzada y mal criada. Ella toda descompuesta le 
repitió que era un 'zambo majadero'. Sabido esto por el Provisor, la excomulgó, y mandó fijar declaratorias, y aun le impuso multa de doscientos pesos. La declaratoria decía así: 'Téngase por pública excomulgada a Marcela Antonia Peñaranda, mujer de don Pedro de Echevarría, por inobediente a los preceptos de Nuestra Madre Iglesia, y por el desacato de haber tratado mal de palabras al señor doctor don Juan José de la Concepción de Rivadeneyra, Arcediano de esta Santa Iglesia; y porque al mismo tiempo trató también mal al doctor don José de Soto, presbítero, que estaba actualmente celebrando'. Dirigió los autos y la decisión el doctor don Manuel Vidal, cura de Calco, abogado y asesor. Hubo varios pareceres acerca de la pena. Primero quisieron ponerla en las Nazarenas y después en la cárcel pública, hasta que últimamente se resolvieron a la excomunión. El día 7 de junio, pasó el padre misionero donde el señor Arcediano doctor Rivadeneyra, para que la perdonase y la hiciese absolver; pero no quiso. Lo mismo contestó al padre mercedario Montoya. Finalmente la absolvieron el 8 de junio, que fue la octava de Corpus, y quitaron las declaratorias. Llámase la hija Rosa y era de la edad de nueve años y media (en Compton, 2000, pp. 21-22).

\subsection{El relato que en la versión de Palma se llama "Historia de una excomunión"}

La tradición de Palma empieza por dar referencias del incidente histórico. Lo que significa que no siempre se presentará como un "parrafillo histórico" de la segunda parte del relato. En esta tradición, el narrador ofrece la información desde el comienzo. Obsérvese que se precisa fechas para que el lector perciba que lo relatado tiene mucho de veraz, aunque sabemos que es verosímil. 


\section{El narrador dice:}

El deán de la Catedral del Cuzco, doctor don Fernando Pérez Oblitas, fue elevado a la categoría de provisor del obispado en sede vacante por fallecimiento del ilustrísimo doctor don Pedro Morcillo, acaecido el Sábado Santo Iro de abril de 1747, precisamente la hora en que las campanas repicaban gloria.

Entre los primeros actos de eclesiástico gobierno del señor deán, hombre más ceremonioso que el día de Año Nuevo, cuéntase un edicto prohibiendo con pena de excomunión mayor ipso facto incurrenda, que los viejos usasen birrete dentro del templo, y otro reglamentando la indumentaria femenina, reglamentación de la cual resultaban pecaminosos los trajes con cauda en la casa del Señor. Es entendido que las infractoras incurrían también en excomunión, pues en la ciudad de los Incas, ateniéndome a las muchas excomuniones de que hace mención el autor del curioso manuscrito Anales del Cuzco, se excomulgaba al más guapo y a la más pintada por un quítame esa pulga que me pica.

[...] Era doña Antonia Peñaranda señora de muchas campanillas, persona todavía apetitosa, que gastaba humos aristocráticos y tenida por acaudalada, como que era de las pocas que vestían a la moda de Lima, de donde le venían todas sus prendas de habillamiento y adorno. Acompañábala su hija Rosa, niña de nueve años, la cual lucía trajecito dominguero con cauda color de canario acongojado.

Principiaba la misa, y todo fue un ver que madre e hija se arrodillaban para persignarse, y gritar con voz de bajo profundo su señoría el arcediano:

-iFuera esas mujeres que tienen la desvergüenza de venir con traje profano a la casa de Dios! iFuera! iFuera! 
Doña Antonia no era de las que se muerden la punta de la lengua, sino de las que cuando oyen el Dominus vobiscum no hace esperar el et cum spíritu tuo. Dominando la sorpresa y el sonrojo contestó:

-Perdone el señor canónigo mi ignorancia al creer que el mandato no rezaba con la niña, además de que no he tenido tiempo para hacerle saya nueva, y la he traído para que no quedara sin misa.

En vez de calmarse con la disculpa, el señor arcediano se subió más al cerezo y prosiguió gritando:

-He mandado que se vaya esa mujer irreligiosa... Bótenla a empellones... iFuera de la iglesia! iFuera!

$[\ldots]$

-Vamos, niña, que no está bien que sigamos oyendo las insolencias de este zambo, borrico y majadero.

-iZambo dijiste? iSanto Cristo de los temblores! ¿Y también borrico? iVálgame los doce pares de orejas de los doce apóstoles!

$[\ldots]$

-iVáyase en hora mala la muy puerca! ¿Yo zambo? ¿Y borrico?

$[\ldots]$

El día siguiente fue de gran alboroto para el vecindario del Cuzco, porque en la puerta de la Catedral, apareció fijado este cartelón: "Téngase por pública excomulgada a Antonia Peñaranda, mujer de don Pedro Echevarría, por inobediente, a los preceptos de Nuestra Santa Madre Iglesia, y por desacato de haber tratado mal de palabras al señor doctor don Juan José de la Concepción de Rivadeneira, y porque con sus gritos desacató también al doctor don José Soto, 
presbítero, que estaba actualmente celebrando el Santo Sacrificio. Nadie sea osado a quitar este papel, bajo pena de excomunión".

[...] Las principales señoras del Cuzco entre las que doña Antonia gozaba de predicamento, varios regidores del Cabildo, el superior de los jesuitas y el comendador de la Merced iban del provisor al arcediano y de éste a aquél, con empeño para que se levantase la terrorífica censura. [...]

El 8 de junio, día en que se celebraba la octava del Corpus, se retiró el cartel de excomunión, y el provisor declaró absuelta e incorporada el seno de la Iglesia a la aristocrática dama que no tuvo pepita en la lengua para llamar zambo, y borrico, y majadero a todo un ministro del altar (1968, p. 582)

En este caso, si hacemos una comparación de la crónica con la tradición, el relato de Palma resulta mejor como estructura, presentación de secuencias, diálogos y discurso. Tiene más claridad y dinámica de acciones. Todo ello influye en el manejo de la intensidad del relato. Está hecho como para que el relato nos conduzca al clímax de la acción. Se mantiene el suspenso hasta saber si el religioso reconsiderará la excomunión. Como se sabe, el buen narrador debe dosificar las acciones, configurar adecuadamente sus personajes, y finalmente, mantener el dinamismo en los diálogos de modo que el imaginario del lector pueda revivir los hechos como si estuviera ante ellos. Y eso es lo que sucede con esta tradición. Los diálogos son verosímiles y el lector hasta puede imaginar a esos personajes. Guardando la distancia, es lo que sucede con Hemingway, a través de sus novelas o relatos, el lector puede visualizar la escena. Esa es la cualidad que no tiene los Anales del Cusco, pero que sí logra, en cierto modo, el Inca Garcilaso y en menor medida el Palentino.

En la tradición analizada, se cuenta que el personaje femenino que había insultado al arcediano fue excomulgada. Y dice el 
narrador que, en esa época, "Una excomunión asustaba en aquellos tiempos como en nuestros días los meetings populacheros" (Palma, 1968, pp. i??). Importante comparación porque al narrador le permite hacer el necesario puente entre los hechos del pasado y el escenario del presente inmediato.

\section{Un relato en la versión de Diego Fernández, el Palentino}

Otra importante relación de la crónica con la tradición de Palma se puede encontrar en el relato que Palma titula "Comida acabada, amistad terminada", y el incidente registrado por Diego Fernández, el Palentino. Veamos lo que consigna el cronista:

Y como llegó [Francisco de Carvajal] a la ciudad de San Miguel de Piura, hizo muestras de querer matar algunos principales de aquel pueblo, y, admitiendo ruegos, les otorgó las vidas y desterró de aquella provincia, quitando los indios que tenían, condenándolos asimismo en mucha cantidad de pesos que luego cobró, que era su final pretensión. Estaba en esta sazón preso en la cárcel pública de la ciudad Francisco Hurtado (vecino de Santiago de Guayaquil) [...]. Entendiendo, pues, Francisco de Carvajal esta prisión, le mandó soltar libremente, reprendiendo a los alcaldes porque tanto tiempo le habían tenido en la cárcel. Los cuales le soltaron luego y fue a dar las gracias de su libertad a Francisco de Carvajal, y él le recibió amorosamente, mostrando pesarle mucho de su larga prisión, porque la verdad de muy atrás habían sido amigos, e hízolo quedar consigo a comer con todo regalo y buen tratamiento, haciéndole muchas ofertas y ofrecimientos. Después que hubieron comido, Francisco de Carvajal envió a llamar al cura del pueblo, y siendo venido, dijo: "Señor Francisco Hurtado, yo he sido siempre amigo y servidor de V. M., y así 
como tal amigo, y como Francisco de Carvajal, yo le saqué de prisión haciéndole aquel tratamiento que V. M. ha visto; y hasta aquí yo he cumplido con la obligación que en amistad debe Francisco de Carvajal a Francisco Hurtado; ahora es menester que yo cumpla también con lo que debo al servicio del Gobernador, mi señor, y así ya no puedo dejar de matar a V. M. Aquí está el padre cura, V.M., se confiese, porque yo no puedo hacer otra cosa". Y hablándole desta suerte, luego le hizo dar garrote (en Compton, 2000, pp. 27-28)

\subsection{La mutación de la crónica a la tradición titulada "Comida acabada, amistad terminada"}

Veamos ahora algunos párrafos significativos de la tradición de Palma, que aparecerá llevando como título "Comida acabada, amistad terminada", un refrán que viene muy al caso por los hechos contados por el Palentino. Entonces, hay allí un mérito por destacar, y es el hecho de encontrar el refrán pertinente y tener la inspiración necesaria para ensamblarlo en la tradición referida.

En el relato, el narrador empieza con la referencia histórica. El narrador considera que el lector debe tener, necesariamente, ese referente:

Tres meses antes de la batalla de Iñaquito, en que tan triste destino cupo al primer virrey del Perú, habían los partidarios de Gonzalo Pizarro puesto preso, en la cárcel de San Miguel de Piura, al capitán Francisco Hurtado, hombre septuagenario, muy influyente y respetado, vecino de Santiago de Guayaquil y entusiasta defensor de la causa de Blasco Nuñez.

Cuarenta días llevaba el capitán de estar cargado de hierros y esperando de un momento a otro, sentencia de muerte, 
cuando llegó a Piura Francisco de Carbajal, en marcha para abrir campaña contra Diego Centeno, que en Chuquisaca y Potosí acababa de alzar bandera por el rey. El alcalde de Piura, acompañado de los cabildantes, salió a recibir a Carbajal, y por el camino le informó, entre otras cosas de que tenía en chirona, y sin atinar a deshacerse de él, al capitán Hurtado (Palma, 1968, p. 88).

Se comenta que Carbajal recordó que conocía al capitán Hurtado de tiempo atrás y que habían sido camaradas de armas: "es muy mi amigo, y juntos militamos en Flandes y en Italia" (ibíd.). Cuando Francisco de Carbajal entró en Piura, el capitán Hurtado ya había sido liberado y fue presto a darle las gracias e hicieron conversación amena acordándose de sus mocedades y aventuras. Se detalla que, a la hora de la comida, estaban allí dos oficiales, un capellán y cuatro vecinos. Fue un momento grato. Y mientras comían:

Ni Hurtado ni Carbajal trajeron para nada a cuento las contiendas del Perú. Bromearon y bebieron a sus anchas, colmando el maestre de agasajos a su comensal. Los dos viejos parecían, en sus expansivas manifestaciones de afecto y de alegría, haberse desprendido de algunas canas. Aquello sí era amistad, y la de Orestes y Pílades pura pampirolada.

Cuando, después de dos horas de banquete y de pronunciar la obligada frase con que nuestros abuelos ponían término a la masticación: Que aproveche como si fuera leche, un doméstico retiró el mantel, la fisonomía de Carbajal tomó aire pensativo y melancólico. Al cabo, y como quien después de meditarla mucho ha optado una resolución, dijo con grande aplomo:

-Señor Francisco Hurtado, yo he sido siempre amigo y servidor de vuesa merced, y como tal amigo le mandé quitar prisiones y sacar de la cárcel. Francisco de Carbajal ha cumplido, pues, para con Francisco Hurtado, las 
obligaciones de amigo y de camarada. Ahora es menester que cumpla con lo que debe al servicio del gobernador, mi señor. ¿No encuentra vuesa merced fundadas mis razones?

-Justas y muy justas -contestó Hurtado, imaginándose que el maestre de campo le proponía con este preámbulo inclinarle a cambiar de bandera, o, por lo menos, a que fuese neutral en la civil contienda.

-Huélgome -continuó Carbajal- de oírlo de su boca, que así deshecho escrúpulos. Vuesa merced se confiese como cristiano que es, y capellán tiene al lado, que yo, en su servicio, no puedo hacer ya más que mandarle dar garrote.

Y Carbajal abandonó la sala murmurando:

-Cumplí hasta el fin con el amigo que buey viejo hace surco derecho. "Comida acabada, amistad terminada". (1968, pp. 88 - 89).

Es notorio que con Fernández nos encontramos ante un relato con el estilo propio del neoclasicismo renacentista, mientras que Palma se esmera en redactar con la idea de relato breve tal como se concebía en el siglo XIX. En cuanto al episodio que se menciona, se puede observar que, inicialmente, Carbajal es presentado como un caballero dadivoso con los amigos, pero que, por encima de lo personal, tiene el deber de ser leal a Gonzalo Pizarro.

Veamos ahora la diferencia discursiva. Mientras Diego Fernández narra que Carbajal dijo:

hasta aquí yo he cumplido con la obligación que en amistad debe Francisco de Carvajal a Francisco Hurtado; ahora es menester que yo cumpla también con lo que debo al servicio del Gobernador, mi señor; y así ya no puedo dejar de matar a V.M. Aquí está el padre cura, V.M., se confiese (en Compton, 2000, p. 28). 
Palma, en su tradición, dice lo mismo, pero hace más verosímil la escena porque inserta un comentario al discurso inicial de Carbajal. Es decir, desglosa el discurso de Carbajal para exponer que ha cumplido con Hurtado, como amigo; y le toca cumplir como militar servidor de Gonzalo Pizarro.

- Señor Francisco Hurtado, yo he sido siempre amigo y servidor de vuesa merced, y como tal amigo le mandé quitar prisiones y sacar de la cárcel. Francisco de Carbajal ha cumplido, pues, para con Francisco Hurtado, las obligaciones de amigo y de camarada. Ahora es menester que cumpla con lo que debe al servicio del gobernador, mi señor. ¿No encuentra vuesa merced fundadas mis razones?" (Palma, 1968, p. 89)

El anuncio de que, por ser leal a su jefe militar, debe darle garrote es un hecho inesperado, una decisión que, al parecer, Carbajal la tenía pensada aún antes de retribuir al amigo con una buena cena. El anuncio cae como un balde de agua fría. Pero es la decisión del maestre de campo y se debe cumplir.

Y viene al caso aquel refrán popular que da título al cuento. Era importante que se agregue ese refrán porque, en el imaginario popular, se producirá una especie de vaso comunicante entre el refrán y el incidente anecdótico que registra el cronista. El lector no dejará de recordar el hecho anecdótico apenas escuche el refrán.

\section{Conclusiones}

1. Las tradiciones peruanas utilizan una propuesta argumental, un episodio anecdótico referido en la crónica del Inca Garcilaso, el texto del Palentino, o de otro documento como el de los Anales del Cusco. Es tal la dependencia que podríamos decir que 
las tradiciones no existirían sin el relato histórico referido en las crónicas.

2. Aunque la crónica debe ser un relato objetivo y sobrio, es un hecho que algunos, como el Inca Garcilaso, no dejan de recrear un relato anecdótico. A su vez, un relato de Palma no deja de utilizar datos de los cronistas o los que encontramos en libros de historia del Perú.

3. En Palma el relato corto tiene un inicio motivador o inquietante, un conflicto enlazado al hecho anecdótico (que se revive en diálogos dinámicos y vivaces) y un desenlace inesperado. Un rasgo muy propio de Palma es que sus relatos tienen un tono y un estilo ameno y diálogos verosímiles.

4. La eficiencia narrativa de Palma tiene que ver con la dosificación del suspenso para mantener el interés del lector. Pero también el uso de una cierta técnica para encontrar el refrán o los decires populares que se ensamblan al relato. No pocas veces hace el puente necesario entre un refrán aún reconocido en el siglo XIX y diríamos en el siglo XX, pero que se remontan al siglo XVI. Así pues, la tradición muestra una historia que no se encierra en el pasado.

5. Palma logra que, debido a las diferentes aventuras y hechos singulares, algunos personajes como Carbajal se conviertan en leyenda. De ese modo lo identificará el imaginario popular.

6. Es importante observar que los cronistas refieren episodios anecdóticos como particularidades u ocurrencias de algún personaje, como Carbajal. No es un relato cerrado y que tenga existencia independiente. Mientras que Palma se basa en el episodio anecdótico que encuentra en la crónica y construye un relato autónomo e independiente. 


\section{Bibliografía}

Acosta, Juan de. (2008). Historia natural y moral de las indias. Madrid: Consejo Superior de Investigaciones Científicas.

Compton, M. (2000). La historicidad de las Tradiciones Peruanas de Ricardo Palma. Lima: Fondo Editorial Biblioteca Nacional del Perú.

Fernández, Diego. (1914 [1571]). Historia del Perú. Madrid, Biblioteca Hispania.

Garcilaso de la Vega, Inca. (2007 [1609]). Comentarios Reales. Lima: Fondo Editorial de la Universidad Inca Garcilaso de la Vega.

Huárag Álvarez, E. (2004). Estructuras y estrategias en la narrativa peruana. Lima: Fondo Editorial de la PUCP.

Oviedo, J. M. (1965). Genio y figura de Ricardo Palma. Buenos Aires: Eudeba Editorial Universitaria.

Palma, R. (1968). Tradiciones peruanas completas. Madrid: Ediciones Aguilar.

Zavaleta, C. E. (1998). "Naturaleza y estructura de la tradición de Palma”. En Aula Palma, revista del Instituto Ricardo Palma.

Recibido el 19 de octubre de 2019 Aprobado el 27 de octubre de 2019 